\title{
WAVE CLIMATE VARIABILITY AND RELATED CLIMATE INDICES
}

\author{
Nobuhito Mori, Kyoto University, mori@oceanwave.jp \\ Risako Kishimoto, Shimizu Corporation, odaiwokudasai@gmail.com \\ Tomoya Shimura, Kyoto University, shimura.tomoya.2v@kyoto-u.ac.jp
}

\section{INTRODUCTION}

Climate change is highly expected to give significant impact on coastal hazards and environment. The future projections of wave climate under global warming scenarios have been carried out and shows changes in wave heights depending on the regions (e.g., Hemer et al., 2013). Beside the long-term trends of wave climate, annual to decadal changes are also important to understand variability. For example, the North Atlantic Oscillation (NAO) is highly correlated to monthly mean wave height along the western European coast. However, variability of wave climate is not well understood over the globe, quantitatively. Additionally, the standard coastal engineers regard stationary process for wave environment for solving coastal problems.

This study analyzes global wave climate variability for the last half century based on principal component analysis of atmospheric forcing (sea surface winds $U_{10}$ and sea level pressure $P$ ) and wave hindcast.

\section{METHODS}

The target of wave climate is monthly mean significant wave height $\mathrm{H}_{\mathrm{s}}$. The numerical analysis was conducted to understand long-term changes and variability of wave climate. First the 55 years wave hindcast $(\Delta x=60 \mathrm{~km})$ was conducted by WaveWatchlll v4.18 (denotes WW3) forced by JRA-55 reanalysis over the globe.

Second, statistical analysis was conducted to estimate contribution of $\mathrm{U}_{10}$ and $\mathrm{P}$ for $\mathrm{H}_{\mathrm{s}}$. The linear multivariate regression model for $\mathrm{H}_{\mathrm{s}}$ combining local grid based atmospheric information $U_{10}$ and $P$, and the global scale principal component analysis (PCA) for pressure field $P$ was constructed and calibrated by the dynamic wave hindcast results by WW3.

$$
\mathrm{Hs}=\mathrm{a}+\mathrm{b}_{1} \mathrm{U}_{10}^{2}+\mathrm{b}_{2} \mathrm{P}+\mathrm{b}_{3} \Delta \mathrm{P}+\sum_{\mathrm{j}}^{\mathrm{n}} \mathrm{c}_{\mathrm{j}} \mathrm{PC}_{\mathrm{j}}
$$

where $\Delta \mathrm{P}$ the spatial gradient of $\mathrm{P}, \mathrm{PC}_{\mathrm{j}}$ the $\mathrm{j}$-th mode principal component $(\mathrm{PC})$ of $\mathrm{P}, \mathrm{C}_{j}$ the its amplitude, $\mathrm{n}$ the total number of $P C$ modes, and $a$ and $b_{i}$, are empirical coefficients, respectively. The PC modes for $\mathrm{P}$ are considered to introduce the large scale atmospheric patterns to each grid information.

\section{RESULTS AND DISCUSSION}

The global wave climate characteristics was analyzed in detail. Fig. 1 shows the correlation coefficient of Eq.(1) and the 55yrs wave hindcast. The global mean correlation coefficients of monthly mean wave heights between Eq.(1) and the hindcast were improved from 0.84 to 0.94 in comparison without PC modes in Eq.(1). The contribution of large scale PC modes to $\mathrm{H}_{\mathrm{s}}$ is significant. The PC modes effects can be regarded remotely generated swells. The analysis combining wave hindcast and its statistical decomposition by Eq.(1) gives variability of wave climate depends on local (wind sea) and large scale atmospheric disturbances (swells).

The effects of swells on $\mathrm{H}_{\mathrm{s}}$ are discussed over the globe. The swells give dominative roles for $\mathrm{H}_{\mathrm{s}}$ more than half of annual variation but related PC modes are different in the regions. For example, Figure 2 shows the individual contributions of each terms in Eq.(1) to $\mathrm{H}_{\mathrm{s}}$ at typical three locations. Although the local point information of $\mathrm{U}_{10}$ and $\mathrm{P}$ is important for $\mathrm{H}_{\mathrm{s}}$, the use of 1$10 \mathrm{PC}$ modes give significant improvement to estimate $\mathrm{H}_{\mathrm{s}}$ by Eq.(1). For example, the PC mode 1 has $25 \%$ contribution to describe $\mathrm{H}_{\mathrm{s}}$ at WNP location in Figure 2 (blue). The PC mode 1 corresponds to North Pacific Index (NP) which relates to inter-annual to decadal variations in the atmospheric circulation in the Pacific. The NP show more than $20 \%$ impact on the large regions in the middle latitude as shown in Figure 2. The similar contribution of large scale climate patterns to $\mathrm{H}_{\mathrm{s}}$ can be seen by Atlantic Oscillations (AO), NAO and others.

The regional wave hindcast $(\Delta x=7 \mathrm{~km})$ were also conducted targeted the WNP by nesting from the global simulation and were analyzed the same way. The contributions of PC modes show fine scale $\mathrm{O}(100 \mathrm{~km})$ regional dependence on $\mathrm{H}_{\mathrm{s}}$ due to sheltering and diffraction of waves by regional bathymetry effects.

\section{CONCLUSION}

The dynamic and statistical wave climate analysis were conducted based on 55yrs wave hindcast. The large scale atmospheric information is estimated by the PCA for pressure fields. The statistical analysis based on PC modes, inter-annual to decadal variations are important understand variability of $\mathrm{H}_{\mathrm{s}}$ both global and regional scale.

\section{REFERENCES}

Hemer, Fan, Mori, Semedo and Wang (2013) Nature Climate Change, 6p., doi:10.1038/nclimate1791.

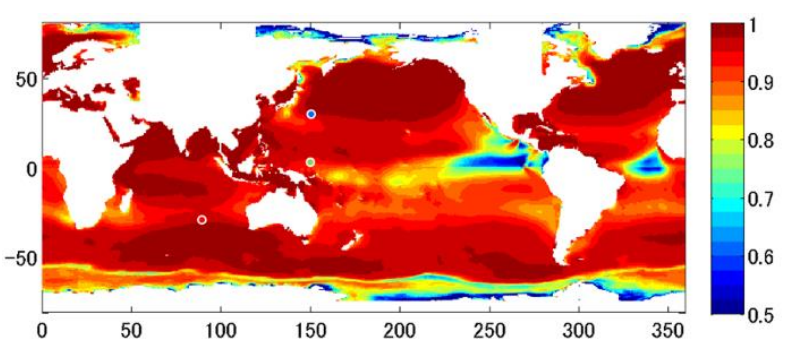

Figure 1 - Correlation coefficient of Hs between Eq.(1) and $55 y$ rs wave hindcast.

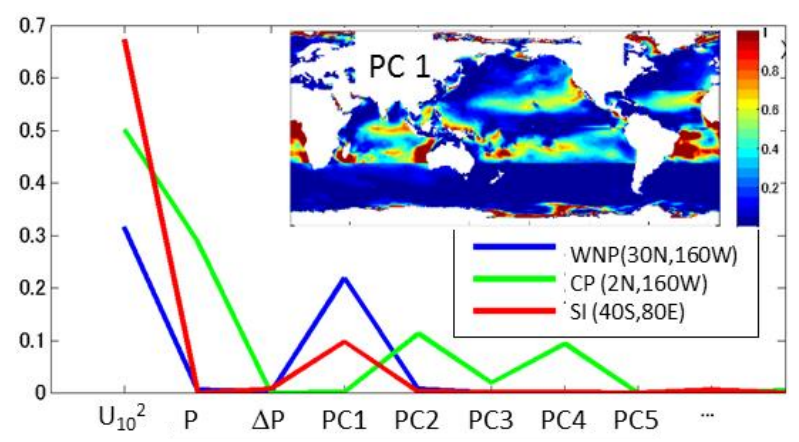

Figure 2 - Contribution of each terms in Eq.(1) to $\mathrm{H}_{\mathrm{s}}$ at typical three locations (WNP: western North Pacific, CP: central Pacific, SI: South Indian; denoted by circles in Figure 1). The contour indicates contribution of PC1 for $\mathrm{H}_{\mathrm{s}}$. 